\title{
Will Greenland melting halt the thermohaline circulation?
}

\author{
J. H. Jungclaus, ${ }^{1}$ H. Haak, ${ }^{1}$ M. Esch, ${ }^{1}$ E. Roeckner, ${ }^{1}$ and J. Marotzke ${ }^{1}$ \\ Received 5 May 2006; revised 26 June 2006; accepted 24 July 2006; published 7 September 2006.
}

[1] Climate projections for the 21st century indicate a gradual decrease of the Atlantic Meridional Overturning Circulation (AMOC). The weakening could be accelerated substantially by meltwater input from the Greenland Ice Sheet (GIS). Here we repeat recent experiments conducted for the Intergovernmental Panel of Climate Change, providing an idealized additional source of freshwater along Greenland's coast. For conservative and high melting estimates, the AMOC reduction is $35 \%$ and $42 \%$, respectively, compared to a weakening of $30 \%$ for the original A1B scenario. Even for the high meltwater estimate the AMOC recovers in the 22nd century. The impact of the additional fresh water is limited to further enhancing the static stability in the Irminger and Labrador Seas, whereas the backbone of the overturning is maintained by the overflows across the Greenland-Scotland Ridge. Our results suggest that abrupt climate change initiated by GIS melting is not a realistic scenario for the $21 \mathrm{st}$ century. Citation: Jungclaus, J. H., H. Haak, M. Esch, E. Roeckner, and J. Marotzke (2006), Will Greenland melting halt the thermohaline circulation?, Geophys. Res. Lett., 33, L17708, doi:10.1029/2006GL026815.

\section{Introduction}

[2] The Thermohaline Circulation (THC) is a global redistribution system in the ocean that carries vast amounts of heat and freshwater. The AMOC is one important part of the THC. Previous model studies [e.g., Cubasch et al., 2001] indicated a considerable decrease of the AMOC and a reduction of the heat transport under global warming conditions. Paleoclimate proxy records suggest that massive and abrupt climate changes occurred in the Northern Hemisphere, in particular during and just after the last glacial, with AMOC changes as the most plausible mechanism [e.g., McManus et al., 2004].

[3] The AMOC in a subset of the Intergovernmental Panel of Climate Change (IPCC) fourth assessment (AR4) projections has been analyzed by Schmittner et al. [2005]. The multi-model study showed a gradual weakening of the AMOC by $25 \%$ until 2100 under the A1B scenario. No model showed an abrupt collapse of the AMOC. The findings are consistent with another model intercomparison study [Gregory et al., 2005] using a more idealized type of increasing greenhouse warming simulations.

[4] Climate models conduct a surface energy balance calculation to determine the temperature of the continental ice sheet. However, the mass of the ice sheet is usually kept constant irrespective of the diagnosed melting or freezing in

\footnotetext{
${ }^{1}$ Max Planck Institute for Meteorology, Hamburg, Germany.
}

Copyright 2006 by the American Geophysical Union. 0094-8276/06/2006GL026815\$05.00 order to ensure conservation of salinity in the ocean. To balance the accumulation of snow on the ice sheet, a runoff or 'calving' scheme is applied. Therefore, in a global warming situation, the models will have increased runoff but the disintegration of the ice sheet, including feedbacks associated with orographic changes, is not properly simulated. Simulations with ice sheet models forced by fluxes from atmospheric models [e.g., Huybrechts et al., 2004] indicated that melting will outweigh accumulation in the mass balance of the entire ice sheet once a certain degree of warming is sustained. The fresh water flow into the ocean is often described in terms of sea level equivalent. For the 21 st century, the projections show a positive contribution of +2 to $+7 \mathrm{~cm}$ from Greenland that is more than offset by ice sheet growth over Antarctica [Huybrechts et al., 2004]. Looking further into the future, however, the model studies predict drastic disintegration of the GIS. Applying rather extreme climate change scenarios, Greve [2000] and Ridley et al. [2005] found a $7 \mathrm{~m}$ sea level rise from Greenland in about 1000 years. The time-mean associated fresh water flux is of the order of $0.1 \mathrm{~Sv}(1 \mathrm{~Sv}=1$ Sverdrup = $10^{6} \mathrm{~m}^{3} \mathrm{~s}^{-1}$ ).

[5] The effect of increasing fresh water input alone has been studied in so-called "water-hosing" experiments. In the model intercomparison study by Stouffer et al. [2006], a fresh water addition of $0.1 \mathrm{~Sv}$ led to an AMOC reduction by 10 to $60 \%$ (30\% for the multi-model ensemble mean), and the associated changes in the heat transport have significant effects on the European climate [Jacob et al., 2005]. There are only a few studies describing global warming experiments with an interactive ice sheet model coupled to an atmosphere-ocean model. In a transient global warming experiment, Fichefet et al. [2003] found a strong and abrupt weakening of the AMOC at the end of the 21 st century. In contrast, Ridley et al. [2005] analyzed a climate with four times the pre-industrial $\mathrm{CO}_{2}$ level and found relatively minor changes in the THC. A simplified land-ice melting scheme was applied in the study by Swingedouw et al. [2006]. In a transient simulation forced by up to four times the pre-industrial $\mathrm{CO}_{2}$ level, the AMOC weakened by $47 \%$ compared to $21 \%$ in the experiment without the melting parameterization. The recent publications underline that the AMOC response to fresh water perturbation is highly model dependent and may be biased by the ability of the models to correctly reproduce the present climate. For example, Fichefet et al. [2003] point to certain weaknesses of the coarse resolution climate model, and the short duration of the simulations. Swingedouw et al. [2006] report a mean state with an AMOC maximum of only $10.4 \mathrm{~Sv}$.

[6] In this study, we use exactly the same model setup as in the Max Planck Institute for Meteorology IPCC simulations, but apply an idealized fresh water source mimicking the melt water from Greenland. Since we do not include the possible negative feedback of melt water induced AMOC 


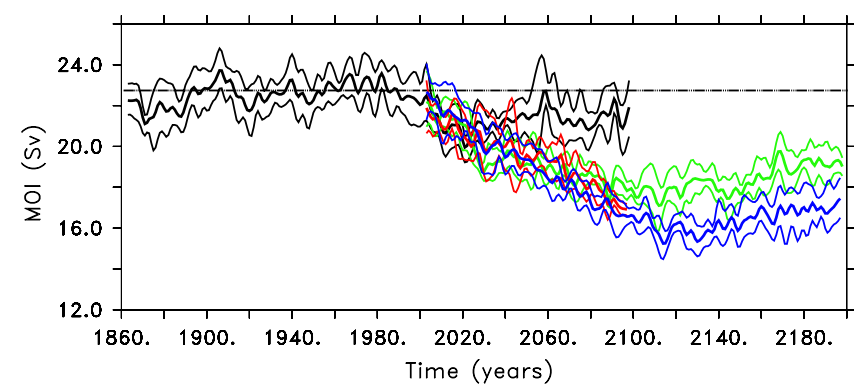

Figure 1. Evolution of the MOI in the MPI-M IPCC simulations 20C/20CC (black), B1 (green), A1B (blue), and A2 (red). For each ensemble of three simulations the ensemble mean (thick line) and spread (maximum and minimum, thinner lines) are shown. A 5-year running mean has been applied. The dashed line is the 20th century mean.

weakening and North Atlantic cooling (which would reduce Greenland melting), the projections of a certain AMOC reduction should be seen as an upper limit for the present model setup.

\section{Model Description and IPCC Experiments}

[7] The climate model simulations are conducted with the coupled atmosphere-ocean-sea ice general circulation model ECHAM5/MPI-OM. The model has no flux adjustments and has been tested for applications under present day conditions [Jungclaus et al., 2006]. The atmospheric part of the model, ECHAM5 [Roeckner et al., 2003], has a horizontal resolution of $1.875^{\circ}$ by $1.875^{\circ}$ (T63) and 31 vertical levels. The ocean/sea ice part of the model, MPI-OM [Marsland et al., 2003], has $1.5^{\circ}$ by $1.5^{\circ}$ horizontal resolution on a curvilinear grid with 40 vertical levels. The grid poles are placed upon Antarctica and Greenland thus avoiding the pole-singularity problem at the North Pole and providing relatively high resolution $(\mathrm{O}(20-40 \mathrm{~km}))$ in the deep water formation regions of the Labrador Sea and the Greenland Sea.

[8] The AR4 20th century (20C) experiments are started from different states of a pre-industrial control experiment and are forced with observed greenhouse gas and aerosol concentration for the period 1860-2000. Thereafter, the concentrations follow the scenarios B1, A1B, and A2 until 2100. In the $20 \mathrm{CC}$ experiments, the $20 \mathrm{C}$ simulations are extended until 2100 with concentrations kept at the year 2000 values, in order to reference the future scenarios against the climate change committed by the 20th century emissions. In $\mathrm{A} 1 \mathrm{~B}$ and $\mathrm{B} 1$, the trace gas concentrations are fixed to the 2100 values for the 22 nd century. All scenario experiments consist of an ensemble of three simulations.

[9] Global annual mean surface air temperatures (SAT, not shown) for the 20th century are similar to observations with increasing warming in the last quarter of the century. In the 21 st century, there is considerable spread, with global warming projections ranging from $2.5^{\circ} \mathrm{C}$ (B1) to $4^{\circ} \mathrm{C}$ (A2) in the year 2100 . In the 20CC simulation, global warming attains $0.5^{\circ} \mathrm{C}$ by 2100 .

[10] In the 20C simulations, the AMOC streamfunction is characterized by a time-mean maximum of $22.5 \mathrm{~Sv}$ at about $35^{\circ} \mathrm{N}$, and the Atlantic outflow is $17 \mathrm{~Sv}$ at $30^{\circ} \mathrm{S}$. The associated maximum northward heat transport is $1.15 \mathrm{PW}$ at $20^{\circ} \mathrm{N}$. Annual mean values of the Meridional Overturning Index (MOI, i.e., the maximum of the AMOC streamfunction between $30^{\circ} \mathrm{S}$ and $90^{\circ} \mathrm{N}$ and below $500 \mathrm{~m}$ ) indicate pronounced interannual to multidecadal variability in the 19th and 20th centuries (Figure 1). The standard deviation of the time series from individual ensemble members is about $1 \mathrm{~Sv}$.

[11] In the 20CC simulations, the MOI decreases by about $2 \mathrm{~Sv}$ by the year 2025 in all ensemble members, indicating the inertia effect of global warming in the transient experiment. Thereafter, there is a slow increase in the MOI until 2100. In the scenario experiments, the MOI reduction continues but there is little difference between the individual scenarios until about 2075. The experiments B1 and $\mathrm{A} 1 \mathrm{~B}$, which are run beyond 2100, show minimum AMOC strengths around year 2125 of $17.5 \mathrm{~Sv}(22 \%)$ and $15.5 \mathrm{~Sv}(30 \%)$, respectively. During the remainder of the 22nd century, both MOI curves show positive trends and regain nearly half of the AMOC reduction by the end of the experiments. The recovery of the AMOC in the 22nd century is due to the salt advection feedback described by Latif et al. [2000]. In the warmer climate, there is more evaporation in the subtropical Atlantic and more lowlatitude water vapor export into the Pacific. The resulting positive salinity anomalies are finally advected into the deep water formation regions in the North Atlantic and decrease the upper ocean stability there.

\section{Estimates of Greenland Melting}

[12] Even though the model does not include an interactive ice sheet model, the melting and accumulation of the glaciers can be assessed a posteriori from the surface heat budget. For the A1B scenario, the respective contributions from Greenland and Antarctica are shown in Figure 2 in terms of the global sea level equivalent. By the year 2100, Greenland melting would lead to a global sea level rise (SLR) of about $10 \mathrm{~cm}$, which is partly offset by ongoing

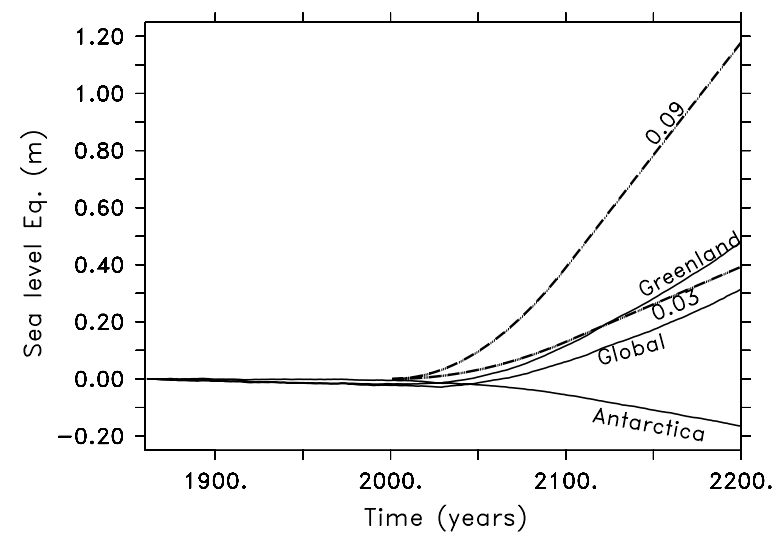

Figure 2. Contribution of Greenland and Antarctica and their combination (global) to sea level rise from an evaluation of the surface heat budget of the IPCC experiments $20 \mathrm{C}$ and $\mathrm{A} 1 \mathrm{~B}$. Also included are the respective effects of an idealized fresh water supply around Greenland as assumed in the $\mathrm{A} 1 \mathrm{~B}+003$ and $\mathrm{A} 1 \mathrm{~B}+0.09$ experiments (dashed lines). 


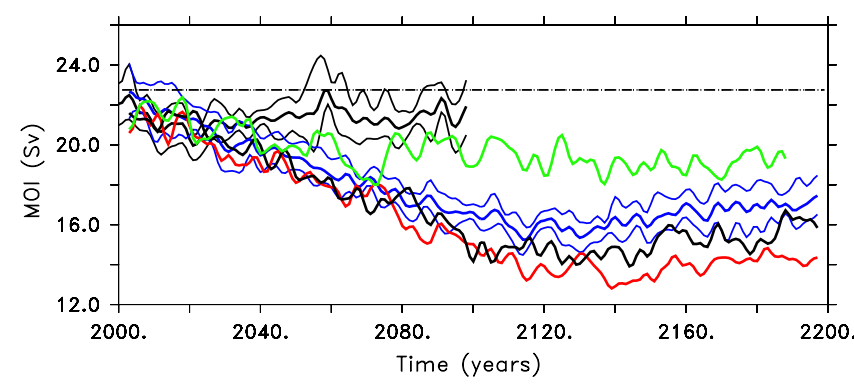

Figure 3. Evolution of the MOI in the Greenland melting experiments $20 \mathrm{CC}+0.09$ (green), $\mathrm{A} 1 \mathrm{~B}+0.03$ (black), and $\mathrm{A} 1 \mathrm{~B}+0.09$ (red) in comparison with the IPCC simulations 20CC and A1B (as in Figure 1).

accumulation over Antarctica. Increasing warming in the 22nd century causes a total SLR of $30 \mathrm{~cm}$ due to changes in the mass balance of ice sheets, with contributions of nearly $+50 \mathrm{~cm}$ from Greenland and $-20 \mathrm{~cm}$ from Antarctica. The melting rates translate to an additional fresh water flux from Greenland of about $0.03 \mathrm{~Sv}$ in the year 2100. For the experiment $\mathrm{A} 1 \mathrm{~B}+0.03$, we therefore prescribe an idealized flux that linearly increases from zero to $0.03 \mathrm{~Sv}$ between 2000 and 2100 and stays constant thereafter (Figure 2). The method does not account for the positive feed back associated with intensified melting as elevation decreases due to melting. Moreover, several recent publications have raised the concern that considering melting alone could underestimate the ice-sheet disintegration [e.g., Zwally et al., 2002]. Therefore we include another experiment $(\mathrm{A} 1 \mathrm{~B}+0.09)$ where the additional fresh water flux is threefold. This amount is of the same order as the fluxes deduced from ice sheet model simulations under relative extreme (up to four times preindustrial $\mathrm{CO} 2$ concentration) climate conditions [e.g., Ridley et al., 2005] and can therefore be regarded as an upper limit on possible melting rates.

[13] In our experiment the melt water is distributed evenly around the Greenland coastline. In addition to the modified A1B experiment, also the 20CC experiment is repeated with the $0.09 \mathrm{~Sv}$ fresh water addition $(20 \mathrm{CC}+0.09)$.

\section{Experiments With Greenland Melt Water Flux}

[14] In the experiment $20 \mathrm{CC}+0.09$, the AMOC weakening is more pronounced than in $20 \mathrm{CC}$, showing a reduction by $3.5 \mathrm{~Sv}(16 \%)$ by the mid 21 st century. Even though the fresh water flux is kept constant over the remainder of the experiment, the MOI stabilizes after 2050 (Figure 3). Unfortunately, lack of computer time did not allow to run the 20CC experiment out to 2200. Earlier experiments where a fresh water flux of similar magnitude $(0.1 \mathrm{~Sv})$ was distributed over the North Atlantic between $50^{\circ} \mathrm{N}$ and $70^{\circ} \mathrm{N}$ [Stouffer et al., 2006] resulted in considerably more pronounced AMOC weakening (about $40 \%$ for a coarse resolution version of ECHAM5/MPI-OM), indicating the important role of localized fresh water input (see below).

[15] In $\mathrm{A} 1 \mathrm{~B}+0.03$ and $\mathrm{A} 1 \mathrm{~B}+0.09$, the fresh water addition from Greenland barely changes the MOI evolution in the first half of the 21st century (Figure 3), but it does cause the AMOC weakening to exceed the ensemble spread of the original A1B simulations around 2080. The AMOC attains minima of $14.5 \mathrm{~Sv}(\mathrm{~A} 1 \mathrm{~B}+0.03)$ and $13 \mathrm{~Sv}(\mathrm{~A} 1 \mathrm{~B}+$ 0.09 ) around 2140 . Hence, the total relative reduction is increased from $30 \%$ for the original A1B ensemble mean to $35 \%(\mathrm{~A} 1 \mathrm{~B}+0.03)$ and $42 \%(\mathrm{~A} 1 \mathrm{~B}+0.09)$, respectively. After 2150, the MOI increases gradually in both cases. Whereas the recovery in the $\mathrm{A} 1 \mathrm{~B}+0.03$ case is similar to the A1B evolution (about $1.5 \mathrm{~Sv}$ in 50 years), the MOI curve for A1B + 0.09 appears somewhat flatter (1 Sv in 50 years) and stays clearly outside the original A1B ensemble spread.

[16] For the North Atlantic climate, the meridional heat transport is more important than the strength of the overturning itself. The heat transport maximum is $1.15 \mathrm{PW}$ in the 20th century, and is reduced by the year 2140 to $0.87 \mathrm{PW}$ in $\mathrm{A} 1 \mathrm{~B}, 0.83 \mathrm{PW}$ in $\mathrm{A} 1 \mathrm{~B}+0.03$, and $0.76 \mathrm{PW}$ in $\mathrm{A} 1 \mathrm{~B}+0.09$ (a reduction of $24 \%, 28 \%$, and $36 \%$ respectively). The reduction in heat transport is smaller than that in mass transport since warmer waters are carried northward with the now slower currents.

[17] The effect of the reduced meridional heat transport on the North Atlantic and European climate is assessed by inspecting the SAT's for the period 2130-2150, when the MOI differences are most pronounced. Comparing the A1B experiment with the 20th climate (Figure 4a), the effect of a weakened THC by the "non-warming" of the North Atlantic between $45^{\circ} \mathrm{N}$ and $65^{\circ} \mathrm{N}$ is clearly identified whereas the zonal average over this latitude band gives a warming of more than $5^{\circ} \mathrm{C}$. The additional effect of the icesheet melt water is restricted to a similar area of the North Atlantic region (Figure 4b). Relative to the A1B scenario, there is a slight cooling that is restricted to the North

a)

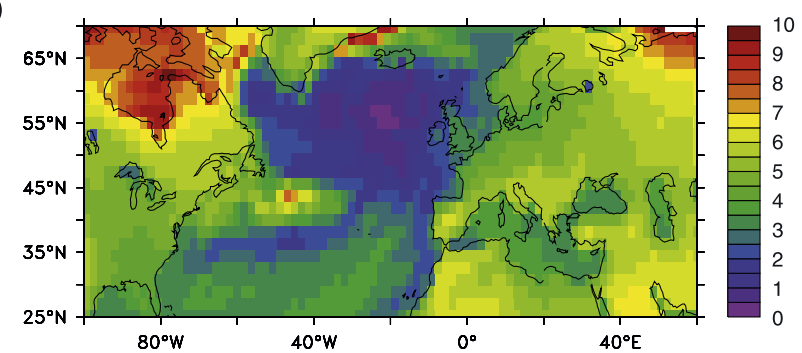

b)

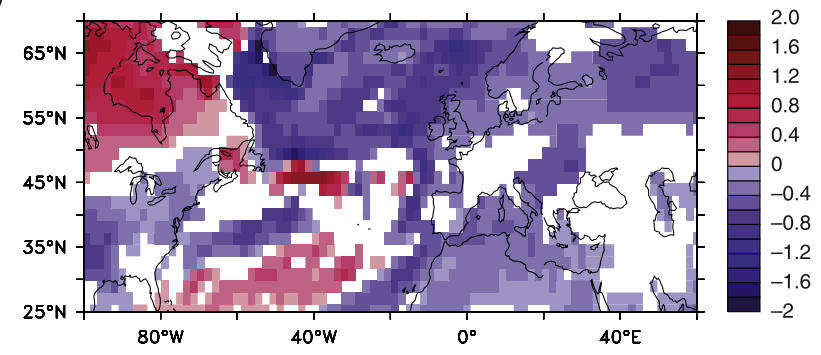

Figure 4. SAT difference between (a) the A1B experiment (ensemble mean, time average 2130-2150) and the 20C ensemble mean (time average 1900-2000), and (b) between the Greenland melting experiments $\mathrm{A} 1 \mathrm{~B}+0.09$ and the regular IPCC A1B ensemble mean for the period 21302150). In Figure $4 \mathrm{~b}$ areas where the difference is less than two times the A1B ensemble standard deviation are blanked out. 
a)
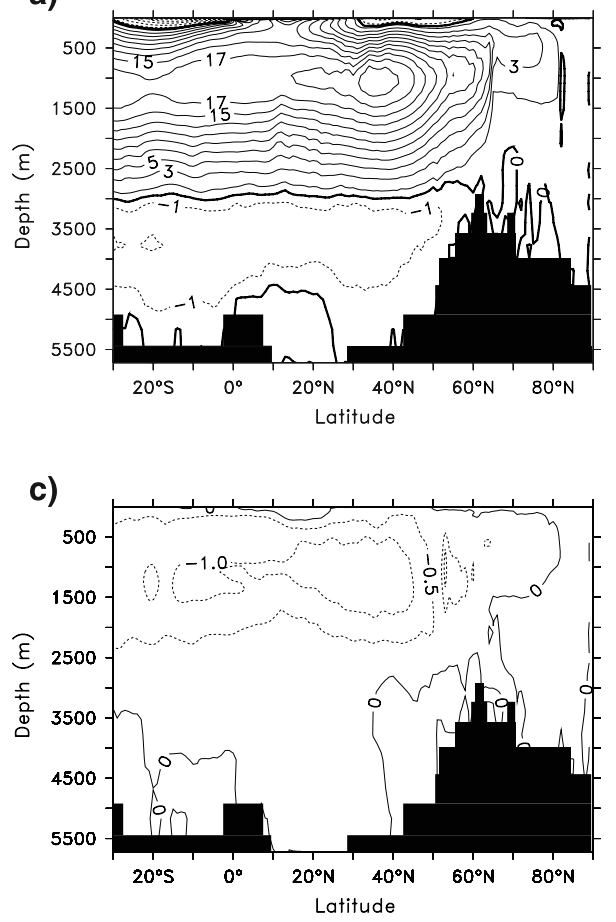

b)

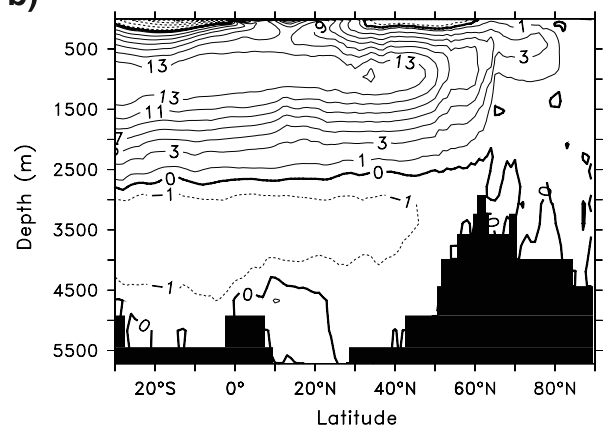

d)

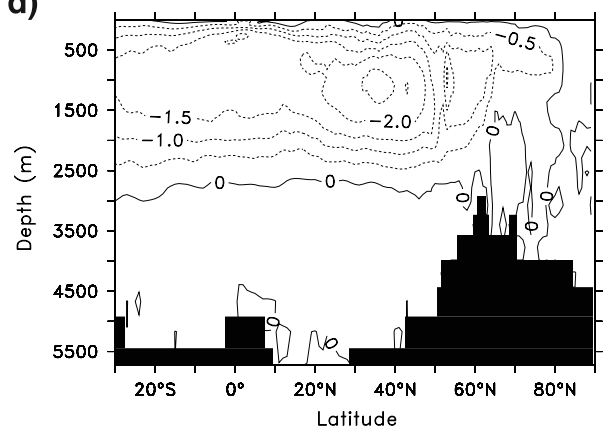

Figure 5. (top) Meridional overturning stream function for (a) the 20th century and (b) the A1B experiment (21302150 mean). (bottom) Differences in the stream functions for the Greenland melting experiments (c) A1B +0.03 and (d) A1B +0.09 and the regular IPCC A1B ensemble mean for the period 2130-2150. Contour interval is 2 SV in Figures 5a and $5 \mathrm{~b}$, and $0.5 \mathrm{~Sv}$ in Figures $5 \mathrm{c}$ and $5 \mathrm{~d}$. Note that the zonally averaged topography does not reflect the real sill depths (600m in Denmark Strait and $900 \mathrm{~m}$ in the Faroe Bank Channel).

Atlantic ocean in the A1B +0.03 simulation (not shown) and hardly exceeds a few tenths of a degree over continental areas in the A1B + 0.09 simulation (Figure $4 \mathrm{~b}$ ).

[18] To understand why the AMOC weakening is relatively moderate we have to analyze its spatial structure. The streamfunction (Figure 5a) is characterized by a maximum at $40 \mathrm{~N}$, but a substantial part of the deep NADW branch stems from the Nordic Seas. A section along the GreenlandScotland-Ridge (GSR) (not shown) reveals that the overflows of dense $\left(\sigma_{\theta}=27.8\right)$ water account for more than $6 \mathrm{~Sv}$ (with almost equal contributions from Denmark Strait and the Iceland-Scotland section), in agreement with Hansen and Østerhus [2000]. In the global warming scenarios the general structure of the AMOC is not changed (Figure 5b). Its weakening is concentrated mainly in the North Atlantic Deep Water (NADW) cell between $30^{\circ} \mathrm{N}$ and $55^{\circ} \mathrm{N}$. In contrast, the northern branch of the streamlines that reach into the Nordic Seas stays almost intact. Similarly, in the Greenland melting experiments, the additional reduction in the NADW cell strength (Figures $5 \mathrm{c}$ and $5 \mathrm{~d}$ ) is seen mainly in the subtropical and subpolar region south of the Greenland-Scotland Ridge (GSR). Only in the A1B +0.09 experiment is there a $0.5 \mathrm{~Sv}$ reduction north of the GSR.

[19] In the present day climate, deep-water formation in the model takes place both to the north and to the south of the GSR. In the A1B simulation, winter mixed layer depths are reduced drastically in the Labrador Sea, to the south of Greenland, and in the Nordic Seas. While the convection in the Labrador Sea immediately affects the AMOC [Latif et al., 2006], the dense overflows are a product of the hydraulic system controlled by the GSR and their strength does not directly depend on deep convection in the Greenland Sea [Mauritzen, 1996]. For the hydraulics of the overflows it is more important that a certain density contrast between the Nordic Seas and the North Atlantic south of the GSR is maintained. In fact, the zonally averaged streamfunction gives only a coarse image of the processes involved. The overflow transports across the GSR do even slightly increase in the A1B experiments. Moreover, the Denmark Strait overflow evolves quite similarly in the experiments A1B, A1B + 0.03, and A1B + 0.09: The transport increases from about $2.8 \mathrm{~Sv}$ in the 20th century to more than $3 \mathrm{~Sv}$ by the year 2100 and then decreases to 2.6-2.8 Sv in the 22nd century (M. Lin, personal communication, 2006). Relative changes in the Greenland melting experiments are slightly greater in the Faeroe Bank Channel outflow. The effect of additional melt water input from Greenland is restricted to a further reduction of Labrador Sea convection, more pronounced in the experiment with $0.09 \mathrm{~Sv}$ fresh water input. To the east of Greenland, the fresh water is swept away southward with the East Greenland Current (EGC). There are only minor further changes in the Nordic Seas and the overflow transports are largely unaffected.

\section{Summary and Discussion}

[20] Even though we diagnose a significant effect of the GIS melt water on the strength of the AMOC, its overall characteristic is not changed and there is no indication of a shut down for realistic climate change scenarios. The main 
reason why the AMOC does not react more dramatically to a considerable melt water input from Greenland is the relative robust nature of the overflows across the GSR. In the warmer climate, the density of the overflow waters is drastically reduced, but the hydraulic system of the overflows still operates. The overflows and the subsequent entrainment at the flanks of the GSR provide the core of the NADW overturning cell. Drastic reduction of the Labrador and Irminger Sea convection therefore has only a limited effect on the AMOC strength. Similar findings on the AMOC evolution are also reported by $\mathrm{Hu}$ et al. [2004] analyzing global warming experiments with the National Center for Atmospheric Research (NCAR) Parallel Climate Model: Overall weakening of the THC from sources to the south of Greenland and increasing overturning in the Nordic Seas.

[21] Several studies have investigated the sensitivity of the THC to greenhouse-gas induced warming in various models. An important finding is that some models are more sensitive to changes in the fresh water fluxes, whereas others react more directly to the warming in high latitudes [Gregory et al., 2005]. The latter is also the case for our model so that a modification of the water fluxes will have a limited effect on the weakening of the THC. Model resolution and the parameterization of sub-grid scale processes certainly play a role in the ability of the models to realistically simulate the AMOC components deep water formation, lateral and vertical mixing, or the overflows. For example, the coarse resolution climate model coupled to a comprehensive ice sheet model by Fichefet et al. [2003] simulated deep water formation only to the south of Greenland, owing to too much sea ice cover in the Nordic Seas. According to the results found here, this would explain the higher sensitivity of that model to an even smaller fresh water flux from Greenland. On the other hand, Swingedouw et al. [2006] relate the weak overturning in their control experiment to the absence of Labrador Sea convection. As has been shown by Tziperman [1997], the weak mean state itself may be responsible for the relatively high sensitivity to fresh water additions in that model. The reason why climate models still differ quite considerably in this aspect has to be investigated in more detailed studies using the data from existing and upcoming model intercomparisons.

[22] Acknowledgments. This research was financed in part by the German Ministry for Education and Research (BMBF) under the CLIVAR Project (03F0377F). The suggestions by two anonymous reviewers helped to improve the manuscript. The model simulations were done at the German Climate Computing Center (DKRZ) in Hamburg.

\section{References}

Cubasch, U., et al. (2001), Projections of future climate change, in Climate Change 2001: The Scientific Basis, edited by J. T. Houghton et al., pp. 525-582, Cambridge Univ. Press, New York.
Fichefet, T., C. Poncin, H. Goosse, P. Huybrechts, I. Janssens, and H. Le Treut (2003), Implications of changes in freshwater flux from the Greenland ice sheet for the climate of the 21 st century, Geophys. Res. Lett., 30(17), 1911, doi:10.1029/2003GL017826.

Gregory, J. M., et al. (2005), A model intercomparison of changes in the Atlantic thermohaline circulation in response to increasing atmospheric $\mathrm{CO}_{2}$ concentration, Geophys. Res. Lett., 32, L12703, doi:10.1029/ 2005GL023209.

Greve, R. (2000), On the response of the Greenland Ice sheet to greenhouse climate change, Clim. Change, 46, 289-303.

Hansen, B., and S. Østerhus (2000), North Atlantic-Nordic Sea exchanges, Prog. Oceanogr., 45, 109-208.

$\mathrm{Hu}$, A., G. A. Meehl, W. M. Washington, and A. Dai (2004), Response of the Atlantic thermohaline circulation to increased atmospheric $\mathrm{CO}_{2}$ in a coupled model, J. Clim., 17, 4267-4279.

Huybrechts, P., J. Gregory, I. Janssens, and M. Wild (2004), Modelling Antarctic and Greenland volume changes during the 20th and 21 st centuries forced by GCM time slice integrations, Global Planet. Change, 42, 83-105.

Jacob, D., H. Goettel, J. Jungclaus, M. Muskulus, R. Podzun, and J. Marotzke (2005), Slowdown of the thermohaline circulation causes enhanced maritime climate influence and snow cover over Europe, Geophys. Res. Lett., 32, L21711, doi:10.1029/2005GL023286.

Jungclaus, J. H., M. Botzet, H. Haak, N. Keenlyside, J.-J. Luo, M. Latif, J. Marotzke, U. Mikolajewicz, and E. Roeckner (2006), Ocean circulation and tropical variability in the coupled model ECHAM5/MPI-OM, J. Clim., 19, 3952-3972.

Latif, M., E. Roeckner, U. Mikolajewicz, and R. Voss (2000), Tropical stabilization of thermohaline circulation in a greenhouse warming simulation, J. Clim., 13, 1809-1813.

Latif, M., C. Böning, J. Willebrand, A. Biastoch, J. Dengg, N. Keenlyside, G. Madec, and U. Schweckendieck (2006), Is the thermohaline circulation changing?, J. Clim., in press.

Marsland, S. J., H. Haak, J. H. Jungclaus, M. Latif, and F. Röske (2003), The Max-Planck-Institute global ocean/sea ice model with orthogonal curvilinear coordinates, Ocean Modell., 5, 91-127.

Mauritzen, C. (1996), Production of dense overflow waters feeding the North Atlantic across the Greenland-Scotland Ridge. part 1: Evidence for a revised circulation scheme, Deep Sea Res., Part I, 43, 769-806.

McManus, J. F., R. Francois, J.-M. Gherardi, L. D. Keigwin, and S. BrownLeger (2004), Collapse and rapid resumption of the Atlantic meridional circulation linked to deglacial climate changes, Nature, 428, 834-837.

Ridley, J. K., P. Huybrechts, J. M. Gregory, and J. A. Lowe (2005), Elimination of the Greenland ice sheet in a high $\mathrm{CO}_{2}$ climate, J. Clim., 18, 3409-3427.

Roeckner, E., et al. (2003), The atmospheric general circulation model ECHAM5, part I: Model description, Rep. 349, 127 pp., Max-PlanckInst. für Meteorol., Hamburg, Germany.

Schmittner, A., M. Latif, and B. Schneider (2005), Model projections of the North Atlantic thermohaline circulation for the 21 st century assessed by observations, Geophys. Res. Lett., 32, L23710, doi:10.1029/ 2005 GL024368.

Stouffer, R. J., et al. (2006), Investigating the causes of the response of the thermohaline circulation to past and future climate changes, J. Clim., 19, $1365-1387$

Swingedouw, D., P. Braconnot, and O. Marti (2006), Sensitivity of the Atlantic Meridional Overturning Circulation to the melting from northern glaciers in climate change experiments, Geophys. Res. Lett., 33, L07711, doi:10.1029/2006GL025765.

Tziperman, E. (1997), Inherently unstable climate behaviour due to weak thermohaline ocean circulation, Nature, 386, 592-595.

Zwally, J. J., W. Abdalati, T. Herring, K. Larson, J. Saba, and K. Steffen (2002), Surface melt-induced acceleration of Greenland ice-sheet flow, Science, 297, 218-222.

M. Esch, H. Haak, J. H. Jungclaus, J. Marotzke, and E. Roeckner, Max Planck Institute for Meteorology, Bundesstrasse 53, D-20146 Hamburg, Germany. (jungclaus@dkrz.de) 